\title{
THE REGIONAL AND GEOGRAPHICAL ASPECTS OF FOOD SECURITY: A SPATIAL ANALYSIS IN THE CASE OF AZERBAIJAN, HUNGARY, AUSTRIA, SINGAPORE AND GEORGIA
}

\author{
László VASA ${ }^{1}$ (D), Ragif HUSEYNOV ${ }^{(\mathbb{D})}$, Imre VARGA ${ }^{3}$ (D) Lóránt DÁVID ${ }^{4 *(\mathbb{D}}$
}

DOI: $10.21163 / G T \_2020.152 .16$

\begin{abstract}
Achieving food security is crucial, and a primary development goal world-wide. However, there is a difficulty in finding reliable data on the topic, which raised a problem for policymakers and researchers as well. Therefore, the present study aimed to fill in this gap by examining the dynamics of regional food security. The main research objective was to identify the determinants of food security in Azerbaijan, Singapore, Austria, Georgia and Hungary. Furthermore, a specific objective was to investigate the short- and long-term impacts of both endogenous and exogenous shocks on the food security of the selected countries. The study collected large scale panel dataset between 1992 and 2019. The empirical model suggested that food import, foreign direct investment, inflation, annual per capita income and Human Development Index had a positive, while the flow of food export had an adverse impact on the food security status of the selected countries. The study recommended to the governments of selected countries and to developmental organisations to achieve national food security through indigenous agricultural interventions along with supporting domestic growers by investing in agricultural education, skill development and infrastructure programs.
\end{abstract}

\section{Keywords}

spatial approach, geography of food supply, regional food availability, sustainability

\section{INTRODUCTION}

Under the Sustainable Development Goals (SDG), countries made a commitment to eliminating all kinds of nutritional and food insecurity (UN, 2015; Popp and Lakner and Oláh eds. 2020). And still, food and nutritional insecurity remains one of the most critical sources of hunger and poverty, particularly in the developing world (FAO, 2017a). The prevalence of undernourishment in young children, the micro and macro nutrients deficiency in women are the highest in the less developed countries (Stevens et al., 2015). Many international institutions pay great attention to the food security problems, especially in developing countries, where a huge amount of people suffers from them (Asatiani, 2009). In this regard, Asian nations are facing two major challenges: food insecurity and promotion of trade. Food prices increased in 2007/2008 and have become volatile due to some critical issues and a great threat to food security. Nevertheless, it should be controlled by the cooperation of nations since it is an important factor in preserving regional stability (Chandra and Lontoh, 2010). Food represents the basic need of humans that provides energy for living. In the meantime, Asian countries are facing several other challenges as well, such as high, rapid growth in population, adverse environmental conditions, rural poverty and only a little growth in agriculture (Marzęda-Młynarska, 2017). Problems related to food insecurity arose frequently, their number showed a sharp increase

\footnotetext{
${ }^{1}$ Széchenyi István University, 9026 Györ, Hungary, laszlo.vasa@ifat.hu

${ }^{2}$ Szent István University, Faculty of Economics and Social Sciences, 2100 Gödöllö, Hungary, raqif_h@yahoo.de

${ }^{3}$ Eötvös Loránd University, ELTE Savaria University Centre, Eötvös Loránd University, Faculty of Social Sciences, Institute of Economics, Savaria Department of Business Economics, HU-9700 Szombathely, Hungary, varga.imre@sek.elte.hu

4* Corresponding author, Szent István University, Faculty of Economics and Social Sciences, 2100 Gödöllö, Hungary, david.lorant.denes@szie.hu
} 
between 2007 and 2012. The main reason for food insecurity lies in the inequality of the society where the poor, due to insufficiently available food or not affordable healthy food, suffer from many diseases (Vasa, 2005; Schlichting et al., 2019).

Regional food security has become a sustainable development issue as well in the past few decades (ADB, 2006; Vasa, 2002). A country is said to be food secure when all its people at all times have sufficient economic and physical economic access to nutritious and safe food to meet their food requirements, in order to maintain an active and healthy lifestyle (FAO, 2003). Therefore, this question has become a primary focus of the millennium development goals (MDGs). And as such, food security is observed and examined in the different countries, thus it is measured through the progress of any government, and as part of social well-being (Carter et al., 2010). However, achieving regional and country-level sustainability of food is still a great challenge (Smith, 2011). While many countries have presented social development programs and carried out policy interventions, none of these efforts led to reaching the desired goals (Keszi-Szeremlei and Magda, 2015; Chaaban et al., 2018;). Particularly, food security in Asian countries did not increase enough to meet the regional demand. The gap between the national food supply and demand has led to an increase in the import of food and livestock (Zahrnt, 2011; Vásáry et al., 2013). Furthermore, there is a difficulty in finding reliable data on regional and national food security in the Asian region, which raised a problem both for policymakers and researchers. The policymakers and implementers of the regional food security program have been gradually seeking tools for measuring food security, which are reliable, easy to use and help to interpret the dynamics of food security (Feizizadeh et al., 2015; Godor, 2016). The analysis of regional and national food security determinants and their status is, therefore, useful for not only policymaking but implementation as well (FAO, 2015b). Hence, it is not surprising that there have already been several factors examined empirically that directly or indirectly impacted food security in the Asian region (Islam and Wrong, 2017). However, according to the literature review, no study applied macro-level or large-scale data to estimate the regional dynamics of the food security situation and its key determinants from a macro perspective recently. Studies investigating the determinants of food security while focusing on a target population or maintaining a microperspective could not only mislead policymakers but also could give a spurious situation analysis on Asia or other less developed countries (Oglu, 2018). Therefore, the current paper aims to fill in this gap by examining the dynamics of regional food security. The main research objective is to identify the determinants of food security in Azerbaijan, Singapore, Austria, Georgia and Hungary. These countries have small population size and had quite comparable socioeconomic situations and demographical profile. So, we selected them for examining the food security dynamics. Moreover, a specific objective is to investigate the short- and long-term impacts of both endogenous and exogenous shocks on the food security of the selected countries.

\section{LITERATURE REVIEW}

A few recent papers focused on the analysis of food security, on short- and medium-term. They highlighted that the dynamics of food security were not dependent on the food balance sheets but on the countries' ability to maintain food consumption through domestic food production and to finance food import. On the short-run, hunger was just increased by such social policies as food aid, and on the medium-run, it was maintained by income inequality (i.e. the higher income of certain people). Higher trading prices for food were found beneficial for agricultural development but could not be expected to drive directly the agricultural growth. Herein, two factors were involved: first, the change in trade prices, and then, in response to it, the rise in agricultural production (Herrmann, 2009). For the argument on food security and the increase in agricultural growth, the European Union's Common Agricultural Policy (CAP) was taken under scrutiny. Hunger was and is a major issue in developing countries which unfortunately did not receive the right attention and response from European farmers. Clearly, in order to boost the agricultural sector, financial investments were needed in the developing countries (Zahrnt, 2011). 
Another paper provided knowledge on the agricultural sector's development in Hungary, and explored the creation of an Agricultural Knowledge System (AKS) in the country. Significant changes were implemented in the agricultural sector to beat the challenges of traditional AKS institutions, which sometimes failed to meet new requirements. The study was based on the perspective of a national stakeholder workshop and meetings with professionals, where the literature review gave recommendations for the development of the agricultural sector and the Hungarian AKS institutions, and established a platform or organisation for further communication among concerned parties and for solving the major problems which were related to the creation of the system (Dávid and Szücs 2009). Therefore, the findings are also important in terms of agricultural knowledge in Europe and food security in general (Nemes and High, 2013). Since many developing countries already had to face food insecurity, it is considered as a major issue. Another paper suggested that in order to improve the food security system, a food policy council should be established, and the locally determined work should be promoted. Work might be related to growth and development in the food system. Food policy, as such, has defined many goals and planning schemes, involving food retail, waste management, urban agriculture, community health, and economic development. Although the findings of the study are wide-ranging, the author highlighted the determining role of local government in addressing food security. Therefore, it was found important to provide a toolkit that could guide local governments in that activity, and in developing the aforementioned council, or in conducting local food and environmental research. Hence, with the collaboration of the local government and the community, moving toward food security could be possible (Stevenson, 2013).

According to another study, food availability was determined by local supply through agricultural and industrial activities. In its measurement, the food security was assessed by GIS multi-criteria analysis through the depiction of a food security map. In that map, 905 villages (57 percent of rural area) were found to be located in the insecure zones and 544 villages (22.15 percent of rural area) were found to be located in the secure ones. The results of that research were particularly important for authorities in East Azerbaijan and Iran (e.g. Ministry of Water Resource Management, Ministry of Agriculture, Ministry of Natural Resources) (Feizizadeh et al., 2015). According to Farmar-Bowers (2015), Australia exported more than the half of its agricultural production. According to the study, Australia failed to control its food security problems and to provide a healthy diet for its people, and to expand the natural resources. In the next decades, a lower yield production is expected due to the changing climate conditions and the higher prices, which together will challenge the food supply systems. Australian people had many interests in the food security-related issues partly because food security forms a necessary part of a healthy food plan. This research suggested that a new policy could not be acceptable for problems in food security and agriculture. It used a seven-method structure for the classified goals of economic growth and other techniques for the improvement of food security. The study explained these basic goals and ideas for the improvement of food security and agriculture system and suggested further techniques for the resolution of problems in the food supply system in Australia. In the beginning of the $20^{\text {th }}$ century, the level of expenditure on food was much lower than in recent decades, when food production significantly increased. Moreover, a significant relationship was found between the quality of food and the income level since healthier food was more expensive than simple cereal and fat. Consumer attitude toward food could change due to a change in the level of income. Hence, consumer preference toward choosing food was different in case of people with lower income. The personal income per capita was (and is) higher in the developed regions and lower in the less developed regions, therefore, developed regions spent more money on better quality, healthier food. In the consumer basket, foodstuff accounted for approximately one-third of the overall expenditure.

Another paper explained that the problem of climate change was a major issue in economic growth and identified its effects on the quality of life and standard of living. It had often been assumed that food security and agricultural food production would be affected by climate change. The paper, upon identifying the effects of climate change on food security, gave some recommendations on how to overcome that situation. The study provided much information on the relationship between food security and climate change by critically examining both of them (Islam and Wrong, 2017). Another 
study (Tortajada and Zhang, 2017) proposed some important policies for Singapore's economy, among them to extend the agricultural trade and investment. The authors found that the proposed export-led policies would increase the research and development, the overall national welfare and the control over food insecurity. They explained how the climate condition and some other major problems were related to irrigated agricultural land, hydrography, vegetation, soil erosion and salinity in the respective area. Another research defined the agriculture-related problems in Azerbaijan and the role of the country in economic development. The findings determined the current situation of agriculture and its possible development strategy and priorities (Oglu, 2018). Another study was carried out to investigate the role of price volatility among the import-dependent countries in Central Asia, particularly among wheat exporters in order to check the efficiency of the wheat market. The purpose of the study was to see the availability of wheat on the market so that food insecurity could be reduced. It applied the OLS model and concluded that the major threat to food security in Central Asia was the low production of wheat and the high transporting costs. However, the volatility of prices was also a major issue in the examined countries which also reduced the efficiency of the wheat market. And finally, the food insecurity was just created. According to the study, in order to secure ghee food and to meet the needs of people in these countries, the market infrastructure should be developed, the unofficial payments should be eliminated, and the geopolitical conflicts should be resolved. Thus, the trade-enhancing policies should be linked to wheat sufficiency policies so that food security may improve (Svanidze et al., 2019). Another research examined the four major pillars that might affect food security: the availability of food, the access to it, its utilisation and the stability of food. The issues created around these pillars meant a great challenge that should be resolved. Herein, a systematic study was conducted to analyse the future problems of agriculture and food. According to the findings, both were affected by climate change as well as by many other socioeconomic factors. They also highlighted that political interference was a major issue in some countries where the food departments were not properly established and showed no improvement in self-sufficiency of wheat and other staple foods. The authors suggested that to maximise the effects of the possible policy, actions should be taken by the countries' governments (Calicioglu et al., 2019).

\section{ECONOMETRIC MODELLING FRAMEWORK}

This study assessed the dynamics of food security of five selected regional economies by employing the Panel GMM estimation approach as proposed by Arellano and Bover (1995) and Blundell and Bond (1998). In order to study the empirical dynamics, we will estimate the moment conditions for $f(F P I, \lambda)$ that is used as proxy of the food security (Eq.1):

$$
m\left(\lambda_{0}\right) \cong E\left[f\left(F P I, \lambda_{0}\right)\right]=0
$$

where FPI is the proxy of food security dynamics in a given moment condition $\lambda \neq \lambda_{0}$.

The estimation of moment condition represents the simple average function (Eq.2):

$$
\hat{m}(\lambda) \cong \frac{1}{n} \sum_{n=1}^{n} f(F P I, \lambda)
$$

Let us minimise the $f(F P I, \lambda)$ with respect to the $\lambda$, using the Eq.2. The estimator results will depend on the choice of the norm function as given (Eq.3):

$$
\|\hat{m}(\lambda)\|_{W}^{2}=\hat{m}(\lambda)^{n} W \hat{m}(\lambda),
$$


here $\mathrm{W}$ represents the weight norm function bases of the given data set.

The Eq.4 represents the final equation of the GMM, based on all properties of GMM (consistent, efficient, and asymptotically normal):

$$
\hat{\lambda}=\underset{\lambda \Theta^{-}}{\arg \min }\left(\frac{1}{n} \sum_{n=1}^{n} f(F P I, \lambda)\right)^{n} \hat{W}\left(\frac{1}{n} \sum_{n=1}^{n} f(F P I, \lambda)\right) .
$$

\section{Econometric Model}

$\ln F P I_{i j}=\beta_{i j, 1} F P I_{t-1}+\beta_{i j, 2} C P I+\beta_{i j, 3} F I I+\beta_{i j, 4} F E I+\beta_{i j, 5} P C G D P+\beta_{i j, 6} F D I G D P+\beta_{i j, 7} H D I+\varepsilon_{i j}$

where "I" represents cross section (number of countries) and j represents data spam (1992-2019).

\section{Data Description}

Panel data were used to examine the regional dynamics of food security of selected five economies (Azerbaijan, Singapore, Austria, Georgia, Hungary). The annual data were taken from the World Development Indicators (WDI) published by the World Bank for the period 1992 to 2019. Table 1 represents the detailed description and the unit of all variables used to estimate the dynamics of food security of selected countries.

Table 1

Variable Description

\begin{tabular}{clcc}
\hline Sr. & \multicolumn{1}{c}{ Variables } & Unit & Description \\
\hline \hline 1 & Food Production Index & Index & FS \\
2 & Per capita GDP & Dollar & PCGDP \\
3 & Consumer Price Index & Index & CPI \\
4 & Food Import Index & Percentage (\%) & FII \\
5 & Food Export Index & Percentage (\%) & FEI \\
6 & Human Development Index & Index & HDI \\
7 & Foreign Direct Investment to & Percentage (\%) & FDIGDP \\
\hline \hline
\end{tabular}

\section{RESULTS AND DISCUSSION}

The results of descriptive statistics explain the dynamics of the food security of the selected economies. The value of average food production value is 70.27 , while 339.02 was the maximum and 3.17 was the minimum value, respectively (Table 2). The average ratio of foreign direct investment to GDP was 9.62 percent between 1992 and 2019. The maximum and minimum values of foreign direct investment to GDP were 55.08 to -15.98 percent, respectively, where 55.08 was the maximum foreign direct investment to GDP in the selected countries during 2003. The lowest foreign direct investment to GDP ratio was observed during 2010. Similarly, the average human development index value was around 0.79 , while 0.94 was the maximum and 0.61 was the minimum value of HDI, respectively. The average value of CPI was 89.63 between 1992 and 2019, the maximum and minimum CPI values were 155.22 and 48.02. The average food import index value was about 9.22 , while the average food export index value was 3.60. (Table 2) 
Table 2

Descriptive Statistics

\begin{tabular}{cccccccc}
\hline & FDIGDP & HDI & CPI & FII & FEI & PCGDP & FPI \\
\hline \hline Mean & 9.62 & 0.79 & 89.63 & 9.22 & 3.60 & 25556.85 & 70.27 \\
Median & 7.03 & 0.79 & 86.05 & 5.70 & 3.48 & 30413.93 & 89.68 \\
Maximum & 55.08 & 0.94 & 155.22 & 39.10 & 8.34 & 59754.99 & 339.02 \\
Minimum & -15.98 & 0.61 & 48.02 & 2.26 & 1.11 & 1238.48 & 3.17 \\
Std. Dev. & 13.15 & 0.09 & 25.58 & 7.18 & 1.59 & 19524.17 & 57.46 \\
Skewness & 0.50 & -0.12 & 0.43 & 1.48 & 0.98 & 0.06 & 0.82 \\
Kurtosis & 8.21 & 2.17 & 3.08 & 6.11 & 3.79 & 1.54 & 4.87 \\
\hline \hline
\end{tabular}

Table 3 presents the results of the correlation matrix that explains the dynamics of the food security of the selected regional economies. The main diagonal of the correlation matrix shows the self-association of each variable which was 1 implying that self-association was 100 percent. The estimated results show that the food production index as the proxy of the food security situation is strongly and positively correlated to the foreign direct investment inflow $(\mathrm{r}=0.77)$. Likewise, there is a 0.29 correlation between the food production index and the human development index. The food production index is moderately and positively $(\mathrm{r}=0.55)$ correlated to the consumer price index. The food security situation was massively dependent $(\mathrm{r}=0.63)$ on the food import index. Per capita income also played an important role $(\mathrm{r}=0.61)$ for attaining the regional food security dynamics in the selected countries.

Table 3

Correlation Matrix

\begin{tabular}{|c|c|c|c|c|c|c|c|}
\hline & FPI & FDIGDP & HDI & CPI & FII & FEI & PCGDP \\
\hline FPI & 1.00 & & & & & & \\
\hline FDIGDP & 0.77 & 1.00 & & & & & \\
\hline HDI & 0.29 & 0.64 & 1.00 & & & & \\
\hline CPI & 0.55 & -0.70 & 0.54 & 1.00 & & & \\
\hline FII & 0.63 & 0.31 & -0.78 & -0.16 & 1.00 & & \\
\hline FEI & 0.83 & 0.51 & -0.57 & -0.33 & 0.43 & 1.00 & \\
\hline PCGDP & 0.61 & -0.45 & 0.93 & 0.26 & -0.82 & -0.48 & 1.00 \\
\hline
\end{tabular}

Table 4 reports the estimated results of the panel GMM estimation approach for examining the regional food security dynamics. In order to establish the reliability of the results of the model, the Sargan over identification restriction test was applied as post estimation test (Table 5). Table 4 reports the elasticities, standard error (SE), probability and t-statistics of all model variables, where 
the food production index was the dependent variable. Food security was found to have a positive and statistically significant relationship with it that was explained by its lag values. The result indicates that one percent change in the lag values leads to 0.60 percent increase in food security of selected countries. Similarly, CPI inflation also had a positive and statistically significant relationship with the food security of selected countries. This type of positive relationship suggests that the price of agricultural output is a key motivation for farmers to grow more and more food. The estimated result shows that one percent change in the inflation leads to 0.40 percent increase in food production in the selected countries (Oglu, 2018).

The estimated results show that food import has a positive impact on the food security of Azerbaijan, Singapore, Austria, Georgia and Hungary. The empirical results show that the flow of food import has a positive and significant impact on food security because the national food security of these selected countries largely depends on the import of food products. The coefficient of food import suggests that 1 percent of increase in food import could lead to 0.05 percent increase in national food availability in the selected economies. The evidence exists which supports this long-term positive relationship (Zahrnt, 2011). But long-term estimates show that the food export index has a negative and significant impact on the access to food security. The food export leads to an increase in food insecurity in the selected economies. The estimated results show that one percent change in food export leads to a reduction in the domestic food availability by 0.05 percent. The results suggest that the governments of the selected countries and certain developmental organisations make efforts to achieve national food security through indigenous agricultural interventions, which should support domestic growers by investing in agricultural education and skill development, and infrastructure programs. The ratio of income per capita to and the foreign direct investment to GDP of the selected economies positively affects food security. The estimated coefficient of income per capita and foreign direct investment suggests that one percent increase in the income per capita and FDI inflow leads to an improvement of $0.16 \%$ and $0.08 \%$ in the access to food security on the long-term, respectively. Similarly, HDI as a proxy of human capital and development also has a positive and significant impact on long-term food security dynamics. The coefficient of HDI in the selected economies is interpreted as one percent increase in the quality of human capital that leads to an improvement of 0.045 percent in national food utilisation on the long-term. HDI actually determines food utilisation at national level. The results suggest that human development played a significant role to achieve the sustainable and long-lasting food security goals.

Table 4

Results of Panel GMM estimation approach

\begin{tabular}{|c|c|c|c|c|}
\hline \multicolumn{5}{|c|}{ System dynamic panel-data estimation } \\
\hline \multicolumn{5}{|c|}{ Dependent Variable: Food Production Index } \\
\hline & Coef. & Std. Err. & T-Stat & Prob. \\
\hline $\operatorname{lnFPI} I_{t-1}$ & $0.60 * * *$ & 0.08 & 7.15 & 0.00 \\
\hline $\operatorname{lnCPI}$ & $0.40 * * *$ & 0.12 & 3.41 & 0.00 \\
\hline $\operatorname{lnFII}$ & $0.05 * * *$ & 0.02 & 3.06 & 0.00 \\
\hline InFEI & $-0.05 * * *$ & 0.01 & -3.41 & 0.00 \\
\hline InPCGDP & $0.16^{* *}$ & 0.07 & 2.15 & 0.04 \\
\hline InFDIGDP & $0.08 * *$ & 0.03 & 2.46 & 0.02 \\
\hline lnHDI & 0.045 & 0.08 & 0.55 & 0.81 \\
\hline Constant & $-0.97 * * *$ & 0.18 & -5.43 & 0.00 \\
\hline \multicolumn{2}{|c|}{ Wald chi2(8) } & 285.76 & Prob > chi2 & 0.00 \\
\hline
\end{tabular}

Legend: $* \mathrm{p}<0.10 ; * * \mathrm{p}<0.05 ; * * * \mathrm{p}<0.01$ 
Table 4 results disclose that the long-term coefficient of food import has a significant and positive effect on food production, it indicates that the selected countries' governments are successfully filling in the local food supply and demand gap. The GDP per capita, inflation, FDI and HDI also have a positive and significant impact on food security. In these economies, rural people have limited purchasing power, therefore, they face many problems to access and afford food because of poverty. The rapid urbanisation and urban population growth are inversely correlated to national food security.

Table 5

Sargan post-estimation test

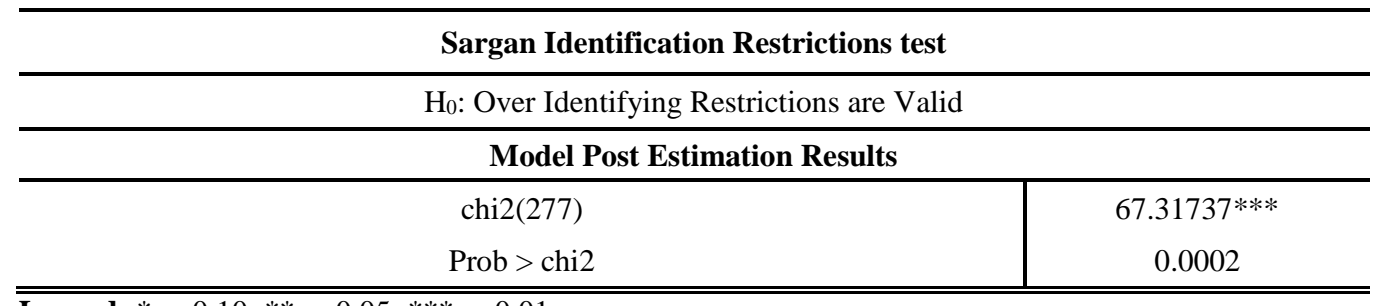

Legend: * $\mathrm{p}<0.10 ; * * \mathrm{p}<0.05 ; * * * \mathrm{p}<0.01$

Table 5 above reports the results of the Sargan test post-estimation for examining the reliability of the model. The Sargan test examines the over identification restrictions of the model. The results show that there was no problem of over identification restrictions in the model and that instrumental variables were uncorrelated with the error term and were correctly specified. The estimated value of the chi square was greater than the critical value of 1,5 , while the level of significance was 10 percent.

\section{CONCLUSIONS AND POLICY RECOMMENDATIONS}

This paper aimed to analyse the dynamics of regional food security in the selected countries, such as Azerbaijan, Singapore, Austria, Georgia and Hungary, by using the panel GMM approach. This approach recommends that food import, FDI, income per capita, inflation and HDI have a positive impact on the dynamics of the national food security in the selected economies. The findings indicate that food security is associated with caloric availability and food consumption in some aspects but not completely. A study by Warrant et al. (2015) similarly found a positive relationship between food availability and food intake and consumption level. It is also essential to identify that food availability does not necessarily attain and improve health and nutritional outcomes (Berti et al., 2004). Our findings suggest a direction for upcoming research: to investigate the health and nutritional characteristics of food security at regional, national and household levels. On the other hand, food export has a negative impact on food availability and access. This finding is quite comparable to existing studies because they also examined food security dynamics and its linages with socioeconomic determinants and human development. Evidence reveals that food import provides a greater access to exclusive food baskets, such as fruits and vegetables, which might increase national food security, and the food accessibility and utilisation of adequate healthy food. Future food security research should also focus on food availability, diversity and quality, more specifically, on vegetable and fruit consumption.

Normally, in the less developed countries, there is a limited adaptive and innovation capacity to develop agriculture, besides there is a limitation on small farmers' agricultural production, and on the creation of income and investment. Our findings show that agriculture may be the only source of rural household income in these countries. The agriculture sector promotes food security by providing income for rural households, to meet their daily needs including the purchase of food. The findings suggest that future food security studies should assess the role of agriculture on intra-household distribution of food (e.g. to vulnerable groups of rural households like children and women). 
Food import in these economies was seen as an effective policy that improved food security at national level and regional level. However, for achieving the sustainable food security goals, trade liberalisation and more economic integration is required, which could bring mutual benefits. These types of trade policies will contribute immensely to the improvement of national and regional food security. Moreover, the GDG 2 (sustainable development goals) target the eradicating of hunger and malnourishment and the attainment of sustainable food security in such countries like Azerbaijan, Singapore, Austria, Georgia and Hungary by the end of 2030. The present paper also helped to provide new knowledge and to enable policymakers to overcome the problem of food insecurity. As we have shown, human development has a potential impact on regional food security dynamics. Although human development is valuable due to its comparability across regions (Maxwell et al., 2008), it may not be the best indicator for food security. Thus, the present study suggests that future studies should pay attention to food access and utilisation in order to achieve long-term food security. This study suggests that the governments of the selected countries and developmental organisations, in their efforts to achieve national food security through indigenous agricultural interventions, should support domestic growers by investing in agricultural education and skill development, and infrastructure programs.

\section{Refer e n e s}

ADB. (2006) Central Asia: Increasing Gains from Trade Through Regional Cooperation in Trade Policy, Transport, and Customs Transit. Philippines: Asian Development Bank.

Berti, P.R., Krasevec, J., M.T.Gamian (2004) A review of the effectiveness of agriculture interventions in improving nutrition outcomes. Public Health Nutrition, 7(5), 599-609.

Asatiani, S. (2009). Food security concept, condition and trends in Georgia. IBSU Scientific Journal, 3(2), 3554.

Calicioglu, O., Flammini, A., Bracco, S., Bellù, L. \& Sims, R. (2019) The future challenges of food and agriculture: An integrated analysis of trends and solutions. Sustainability 11(1), 222.

Carter, K. N., Lanumata, T., Kruse, K. \& Gorton, D. (2010) What are the determinants of food insecurity in New Zealand and does this differ for males and females? Australian and New Zealand Journal of Public Health $4(6), 602-608$.

Chaaban, J., Ghattas, H., Irani, A., \& Alban, T. (2018) Targeting mechanisms for cash transfers using regional aggregates. Food Security 10(2), 457-472.

Chandra, A. C. \& Lontoh, L. A. (2010) Regional food security and trade policy in Southeast Asia: The role of ASEAN. Manitoba: International Institute for Sustainable Development.

Dávid, L. \& Szücs Cs. (2009) Building of networking, clusters and regions for tourism in the Carpathian Basin via information and communication technologies. NETCOM - Networks and Communications Studies 23:1-2. 63-74.

FAO (2015) FAOSTAT statistics database. Food Balance Sheets (Updated Feb 2017).

FAO (2003) World summit on food security: Draft declaration of the world summit on food security. Rome: FAO.

Farmar-Bowers, Q. (2015) Finding ways to improve Australia's food security situation. Agriculture, 5(2), 286312.

Feizizadeh, B., Pourmoradian, S. \& Pourmoradian, S. (2015) Food Security Assessment Based on GIS Spatial Analysis in the Rural Area of East Azerbaijan Province, Iran. GI_Forum, 475-483.

Godor, A. K. (2016) The Major Trends of Food Consumption in Hungary. Deturope-The Central European Journal for Regional Development and Tourism 8(3), 202-211.

Godrich, S. L., Davies, C. R., Darby, J. \& Devine, A. (2017) What are the determinants of food security among regional and remote Western Australian children? Australian and New Zealand Journal of Public Health, 41(2), 172-177.

Hameed, M., Moradkhani, H., Ahmadalipour, A., Moftakhari, H., Abbaszadeh, P. \& Alipour, A. (2019) A Review of 21st Century Challenges in Food-Energy-Water Security in the Middle East. Water 11(4), 682.

Herrmann, M. (2009) Food security and agricultural development in times of high commodity prices (No. 196). United Nations Conference on Trade and Development.

Islam, M. \& Wong, A. (2017) Climate change and food in/security: A critical nexus. Environments 4(2), 38.

Keszi A. Szeremlei \& Magda R. (2015) Sustainable production and consumption. Visegrad Journal on Bioeconomys and Sustainable Development 4 (2) pp. 57-61. 
Marzęda-Młynarska, K. (2017) Food Security Governance in the Southeast Asia Region: from National to Regional Governance. Historia i Polityka 27(20), 31-48.

Maxwell, D. \& Caldwell, R. (2008) Measuring food insecurity: can an indicator based on localized coping behaviours be used to compare across contexts? Food Policy 33, 533-540.

McKay, F. H., Haines, B. C. \& Dunn, M. (2019) Measuring and Understanding Food Insecurity in Australia: A Systematic Review. International Journal of Environmental Research and Public Health, 16(3), 476.

Nemes, G., \& High, C. (2013) Old institutions, new challenges: the agricultural knowledge system in Hungary. Studies in Agricultural Economics, 115(2), 76-84.

Oglu, A. Z. H. (2018) Agriculture in Azerbaijan and its Development Prospects. International Journal of Medical and Biomedical Studies 2(4).

Popp, J (Ed.), Lakner, Z. (Ed.), Judit Oláh (Ed.) (2020) Sustainability in Food Consumption and Food Security Basel, Switzerland, Sustainability, MDPI, 239.

Schlichting, D., Hashemi, L. \& Grant, C. (2019) Infant food security in New Zealand: A multidimensional index developed from cohort data. International Journal of Environmental Research and Public Health 16(2), 283.

Smith, C. (2011) Barriers and solutions to achieving food security for New Zealand families (Doctoral dissertation, University of Otago).

Stevens, G.A., Bennett, J.E., Hennocq, Q., Lu, Y., De-Regil, L.M., Rogers, L., Danaei, G., Li, G., White, R.A. \& Flaxman, S.R. (2015) Trends and mortality effects of vitamin A deficiency in children in 138 low-income and middle-income countries between 1991 and 2013: a pooled analysis of population-based surveys. Lancet Glob. Health 3, e528-e536. https://doi.org/10.1016/S2214-109X(15)00039-X.

Stevenson, S. (2013) Edible impact-Food security policy: A review of literature and synthesis of key recommendations for Toi Te Ora-Public Health Service.

Svanidze, M., Götz, L., Djuric, I. \& Glauben, T. (2019) Food security and the functioning of wheat markets in Eurasia: A comparative price transmission analysis for the countries of Central Asia and the South Caucasus. Food Security 1-20.

Tortajada, C. \& Zhang, H. (2016) Food policy in Singapore. Elsevier Food Sciences 1-7.

UN. (2015) Transforming Our World: The 2030 Agenda for Global Action. United Nations, New York Online available at: https://www.eda.admin.ch/content/dam/ agenda2030/en/documents/recent/7603-final-draftoutcome-document-UN-Sept-Summit-w-letter-08072015_EN.pdf

Vasa, L (2002) Behaviour patterns of farm managing households after the agricultural restructuring - socioeconomic analysis. Journal of Central European Agriculture 1 (3) pp. 312-320

Vasa, L. (2005) Economic coherences between food consumption and income conditions in the Hungarian households. Annals of Agrarian Sciences, Vol. 1. pp. 228-232.

Vásáry, M., Vasa, L. \& Baranyai, Zs. (2013) Analysing competitiveness in agro-trade among visegrad countries Actual Problems of Economics 150 (12) pp. 134-145.Warren, E. \& Hawkesworth, S. (2015) Investigating the association between urban agriculture and food security, dietary diversity, and nutritional status: a systematic literature review. Food Policy 53, 54-66.

Zahrnt, V. (2011) Food security and the EU' s common agricultural policy: Facts against fears (No. 01/2011). ECIPE working paper.

Zsarnoczky, M., Zsarnoczky-Dulhazi, F., Gogo Fredrick Collins Adol, Barczak, M., David, L.D. (2019) Food Safety Challenges in the Tourism Processes. Rural Sustainability Research 41 (336) 26-31. 